\title{
Climate change: scenarios, impacts, policy and development opportunities
}

\author{
Carlo Carraro \\ University of Venice, FEEM, CMCC, GGKP and IPCC
}

\begin{abstract}
$\underline{\text { Abstract }}$
This article is divided into three parts. First, it provides an overview of the main outcomes of the last IPCC assessment report, both in terms of economic drivers of greenhouse gas (GHG) emissions, and in terms of impacts of climate change, in particular for the agriculture sector. Then, it focuses on policy options and their optimal design, taking into account technological availability, international cooperation and above all the stringency of the remaining carbon budget. Finally, it analyses the size and direction of investment decisions required to stabilize GHG emissions and their implications for economic development.
\end{abstract}

December 2015. Revised June 2016

Keywords: climate change, climate policy, investments, technology

JEL: Q43, Q48, Q54

This paper is based on the keynote lecture delivered at the 29th International Conference of Agricultural Economists (ICAE2015) and has been prepared for a Special Issue of Agricultural Economics. The author is grateful to colleagues at FEEM and CMCC for helpful comments. All remaining errors are the author's sole responsibility. Correspondence address: Carlo Carraro, Fondazione Eni Enrico Mattei, Isola di San Giorgio Maggiore 8, 30124 Venice - Italy. Email: carlo.carraro@feem.it . 


\section{Introduction}

The present state of climate policy looks quite paradoxical. Notwithstanding more than twenty years of negotiations and emission reduction commitments, global GHG emissions are steadily growing. They never increased as much as in the last ten years. This is not only related to population and economic growth. Even the fossil fuel mix is not improving, with a revival of coal consumption, particularly in Europe.

The recent Paris Agreement is certainly an important turning point in international negotiations on climate policy. About 190 countries committing themselves to controlling their greenhouse gas emissions is a positive historic event, whatever the doubts and misgivings for much that remains to be done to limit the negative impacts that climate change is having on our societies. Nevertheless, even if the agreement is actually implemented, the sum of all nationally determined emission reduction commitments (NDCs) is very unlikely to be sufficient to keep global average temperature increase below $2^{\circ} \mathrm{C}$. According to the UNFCCC (see UNFCCC, 2015a) the aggregate effect of the Paris Agreement will be a temperature increase of about $3^{\circ} \mathrm{C}$ by the end of the century, unless much more ambitious GHG emission reductions are implemented after 2030.

The long-term scenarios developed by the IPCC (see IPCC, 2104) are clear about emissions and temperature change beyond 2030 . The $2^{\circ} \mathrm{C}$ emission reduction pathway would be excessively costly for both developed and developing economies, or even unfeasible, unless: (i) the annual flow of GHG emissions moves quickly towards zero, and (ii) new technologies to remove the present stock of GHGs from the atmosphere at a large scale become available in the second half of this century.

With the present knowledge and technologies, and the emissions reductions planned in Paris, therefore, the $2^{\circ} \mathrm{C}$ degree target is unlikely to be achieved.

Mitigation efforts are therefore only one of the objectives of climate negotiations. As explicitly mentioned in the Paris Agreement (see UNFCCC, 2015b), efforts and resources should also be devoted to. (i) adaptation to unavoidable climate change and (ii) to compensate vulnerable countries for climate-related losses and damages.

More generally, the recognition that the present effort to reduce emissions, albeit sufficient to reduce the probability of business as usual catastrophic emission increase, is not sufficient to offset some important impacts of climate change, led many policymakers to invest more resources into adaptation to climate change. In addition, new financial mechanisms to help countries suffering from natural disasters and economics losses induced by climate change have been devised. It is therefore no surprise that finance for adaptation and loss and damages compensation are important elements of the Paris Agreement.

The good news is that financial resources to support mitigation investments and adaptation measures are steadily growing. About 390 billion dollars have been devoted to mitigation and adaptation investments in 2014 (Cf. OECD, 2015), even though only 7\% of this amount has been spent on adaptation projects. The Green Climate Fund is planned to reach 100 billion dollars by 2020 and other financial regional or sectoral mechanisms are likely to emerge soon. Climate change is therefore seen as a business and/or development opportunity in many countries. In developed countries, because climate change mitigation and adaptation provide new modern infrastructures and help enhancing economic development. In developed countries because new business opportunities and additional financial resources are offered to companies operating in the energy and water sectors, construction industry, health and education, etc. 
What are then the likely future scenarios for negotiations on emission control, the transition to a lowcarbon economy, and for the new finance of climate change? This lecture attempts to provide a detailed overview of the main scientific, economic and environmental trends of climate policy, its effectiveness and costs, and its financing mechanisms.

\section{Emission Scenarios}

As shown in Figure 1 from the last IPCC assessment Report (IPCC, 2014), GHG emissions rose in the past decade more than in the previous three decades, despite the concern for climate change, the ongoing negotiations and the many IPCC reports. $80 \%$ of total emissions come from fossil fuels. More than half of cumulative $\mathrm{CO} 2$ emissions between 1750 and 2100, about $1100 \mathrm{GtCO} 2$ out of $2000 \mathrm{GtCO} 2$, have occurred in the last 40 years. About $75 \%$ of the $10 \mathrm{GtCO}$ eq growth in annual anthropogenic GHG emissions between 2000 and 2010 comes from the energy supply and industry sectors.

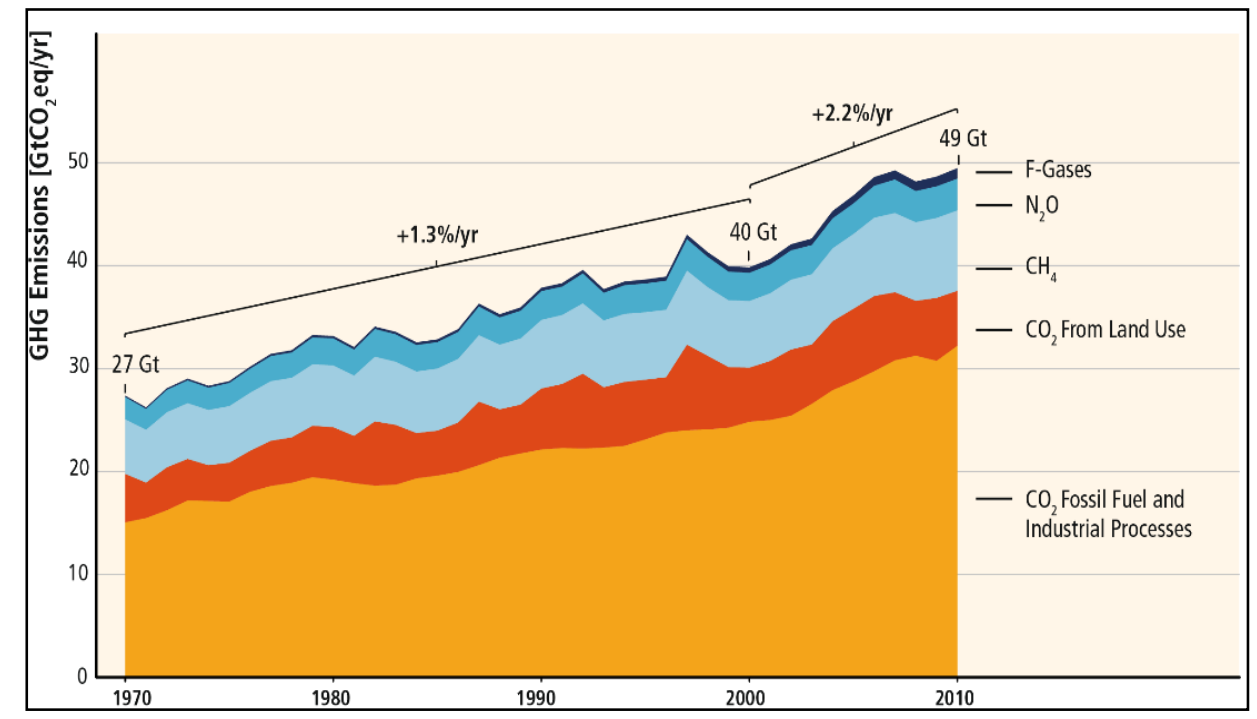

Figure 1: Emission growth since 1970.

Source: IPCC AR5 - WG3 "The Mitigation of Climate Change", 2014

Most of the emissions growth before 1970 took place in industrialized countries. However, most of the recent emission increases have been concentrated in the fastest growing regions in the developing world. From 2000 to 2010 about $75 \%$ of the 10 GtCO2eq increase in total annual GHG emissions took place in upper-middle income countries (see Figure 2). 


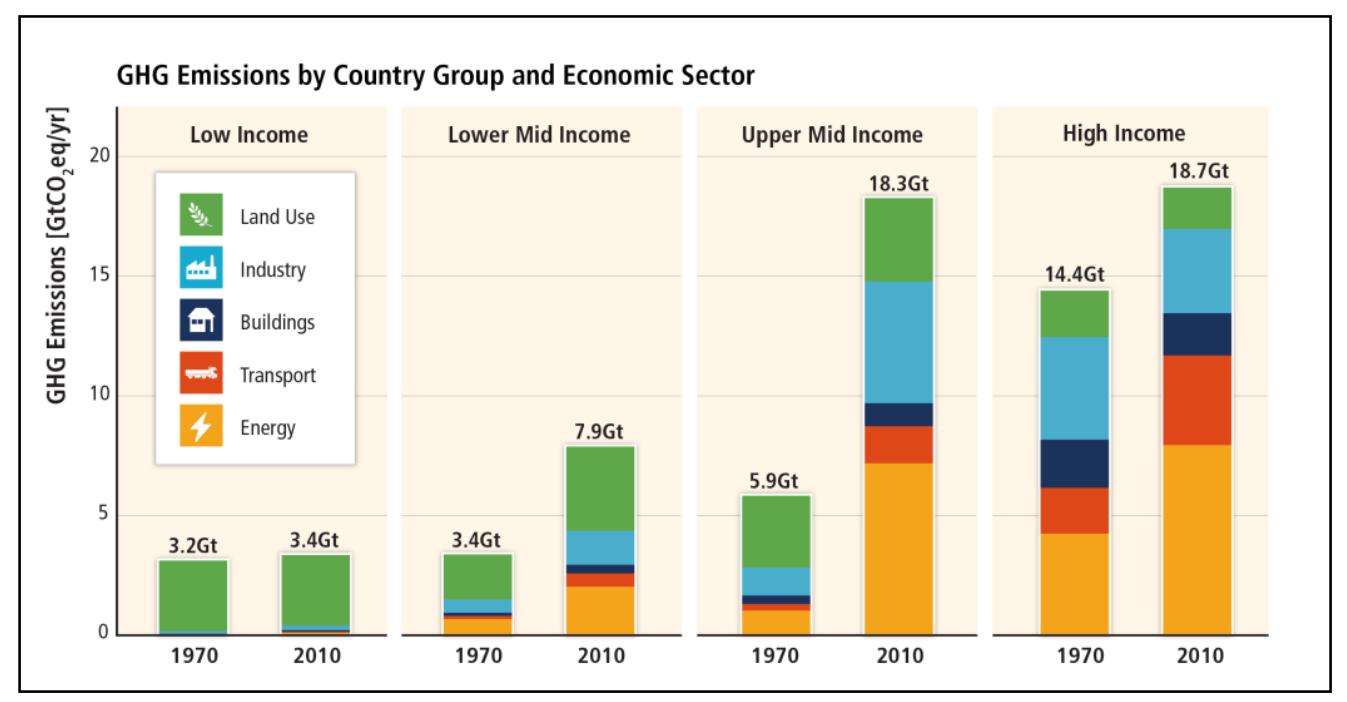

Figure 2: Regional patterns of GHG emissions since 1970.

Source: IPCC AR5 - WG3 "The Mitigation of Climate Change", 2014

Over the last decade the contribution of economic growth to rising total $\mathrm{CO} 2$ emissions from fossil fuel combustion has increased sharply while the contribution of population has remained roughly steady. Between 2000 and 2010 both outpaced emission reductions from improvements in energy intensity (see Figure 3). Increased use of coal relative to other energy sources has reversed the long-standing trend of gradual de-carbonization of the world's energy supply.

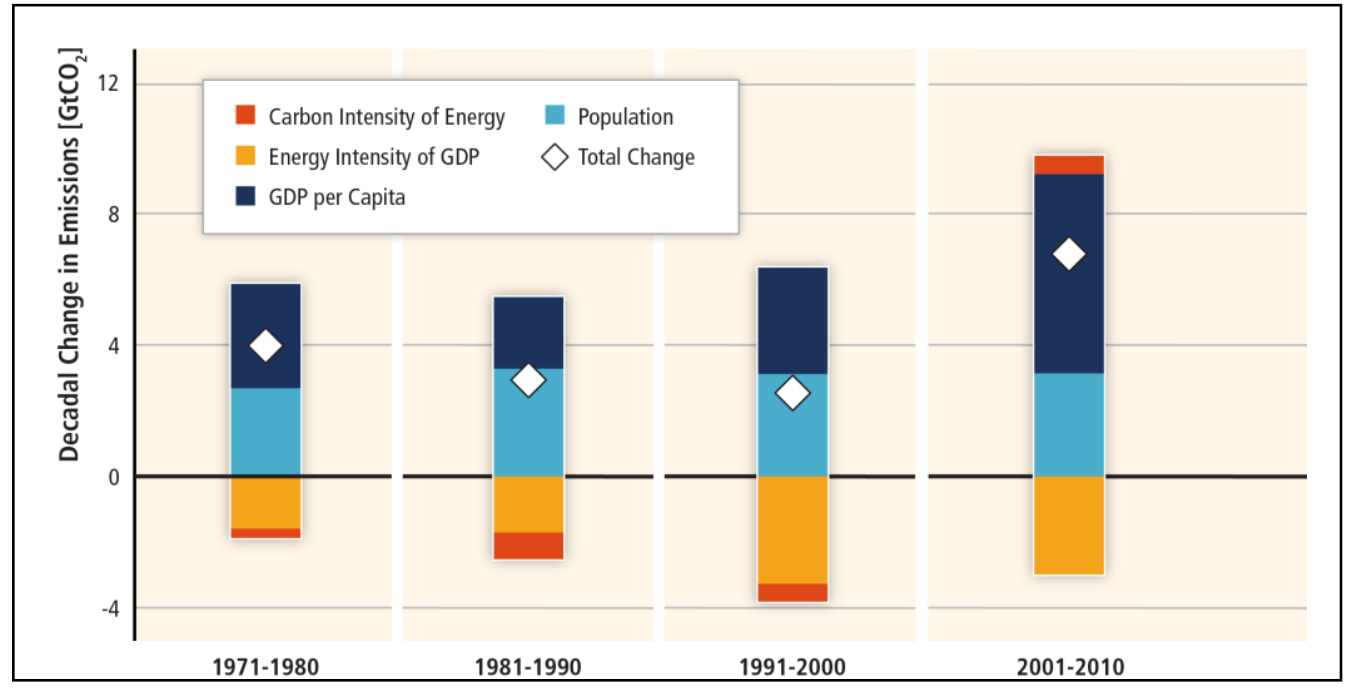

Figure 3: Decomposition of GHG emission growth since 1970.

Source: IPCC AR5 - WG3 "The Mitigation of Climate Change", 2014 
The prospective scenarios for temperature change are therefore quite pessimistic, notwithstanding the decisions adopted in Paris at COP 21. Without additional efforts to reduce GHG emissions, emissions growth is expected to persist driven by population and economic activity. Scenarios without additional mitigation result in median temperature increases in 2100 from roughly $3^{\circ} \mathrm{C}$ to $5^{\circ} \mathrm{C}$ compared to pre-industrial levels. Even higher temperatures cannot be excluded due to climate response uncertainties (IPCC, 2014). Scenarios taking into account the NDCs adopted in Paris results in median temperature increases in 2100 from roughly $2.7^{\circ} \mathrm{C}$ to $3.5^{\circ} \mathrm{C}$ (UNFCCC, 2015).

GHG concentrations are already above $400 \mathrm{ppm}$ and keep growing at about $3 \mathrm{ppm}$ per year. The more than nine hundred mitigation scenarios collected by the IPCC - based on published integrated models - show that mitigation scenarios in which it is likely that the warming caused by anthropogenic GHG emissions can be kept to less than $2^{\circ} \mathrm{C}$ since pre-industrial times are characterized by atmospheric concentrations in 2100 of about 450 ppm CO2eq. Mitigation scenarios reaching concentration levels of about 500 ppm CO2eq by 2100 are more likely than not to limit temperature change to less than $2^{\circ} \mathrm{C}$ relative to pre-industrial levels, unless they temporarily "overshoot" roughly 530 ppm CO2eq before 2100, in which case they are about as likely as not. Scenarios that exceed $580 \mathrm{ppm}$ CO2eq during the course of the century and then sharply decline are unlikely to keep temperatures below $2^{\circ} \mathrm{C}$. Therefore, GHG concentrations are likely to be above the limit consistent with the $2^{\circ} \mathrm{C}$ target within about 20-30 years.

Reaching atmospheric concentrations levels of about $450 \mathrm{ppm}$ CO2eq by 2100 would require substantial cuts in anthropogenic GHG emissions by mid-century through fundamental changes in energy systems and potentially the land surface. Scenarios reaching these end-of-century concentrations are characterized by global GHG emissions reductions of $40 \%$ to $70 \%$ by 2050 compared to 2010 and a tripling to nearly a quadrupling of the share of zero- and low carbon energy supply from renewables, nuclear energy and fossil energy or bioenergy with carbon dioxide capture and storage (BECCS) by the year 2050.

Most importantly, mitigation scenarios reaching about 450 ppm CO2eq in 2100 typically involve temporary overshoot of atmospheric concentration levels and rely on the availability and widespread deployment of carbon dioxide removal (CDR) technologies in the second half of the century. In most scenarios, carbon dioxide is removed from the atmosphere through BECCS. Another CDR option, large-scale afforestation, is also included in some scenarios. The availability and scale of CDR technologies is uncertain and CDR technologies are associated with a diverse set of mitigation risks (see Tavoni and Socolow, 2013).

\section{The Role of the Agriculture Sector}

Agriculture is characterized by a bi-directional relationship with climate change. It is at a time a source of emissions and of abatement options, thus impacting the climate change process; it is also probably the most impacted by climate change among economic sectors. As for the first aspect, agriculture, forestry (i.e. de-forestation) and other land uses (AFOLU) accounted in 2010 for $24 \%$ of direct and $0.87 \%$ of indirect $\mathrm{CO}_{2}$ equivalent emissions (Figure 4). 


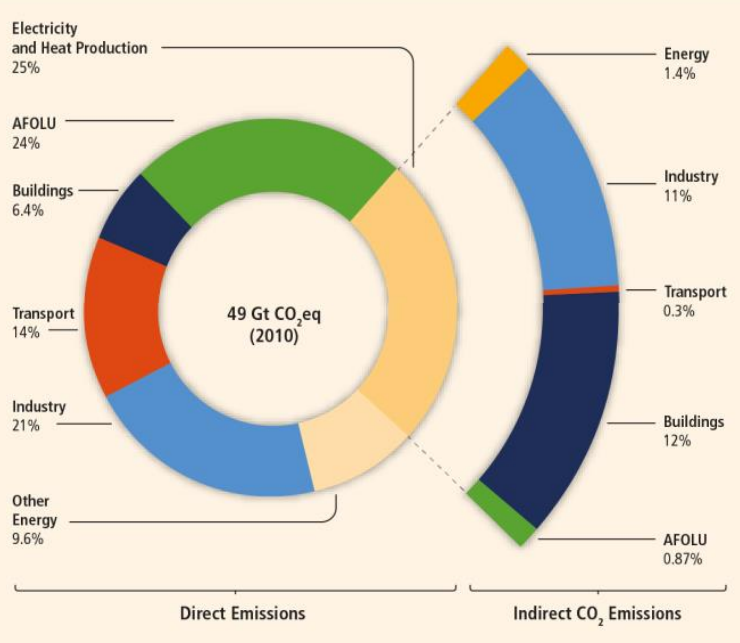

Figure 4: Emissions by source in 2010

Source: WGIII IPCC AR5 (2014), Summary for Policymakers

Furthermore, agricultural activity is one of the main sources of $\mathrm{CH}_{4}$ and $\mathrm{N}_{2} \mathrm{O}$ emissions accounting in 2010 for a share of $40 \%$ and $70 \%$ of the two respectively. Although forests are net sinks of $\mathrm{CO}_{2}$, de-forestation activities are the main source of AFOLU emissions; $\mathrm{CH}_{4}$ emissions from livestock enteric fermentation, specific of agricultural activities, come second (Figure 5 left). Nearly $40 \%$ of AFOLU emissions take place in Asia (Figure 5 right). To understand the importance of climate factors for agriculture, it is sufficient to consider that the production activity that transforms inputs into agricultural outputs involves direct use of weather inputs: temperature, solar radiation available to the plant, $\mathrm{CO}_{2}$ and precipitation. Therefore, agriculture has always been highly dependent on climate patterns and variations such as the warming and drying trend, extreme temperature and precipitation, carbon dioxide fertilization and even ocean acidification.

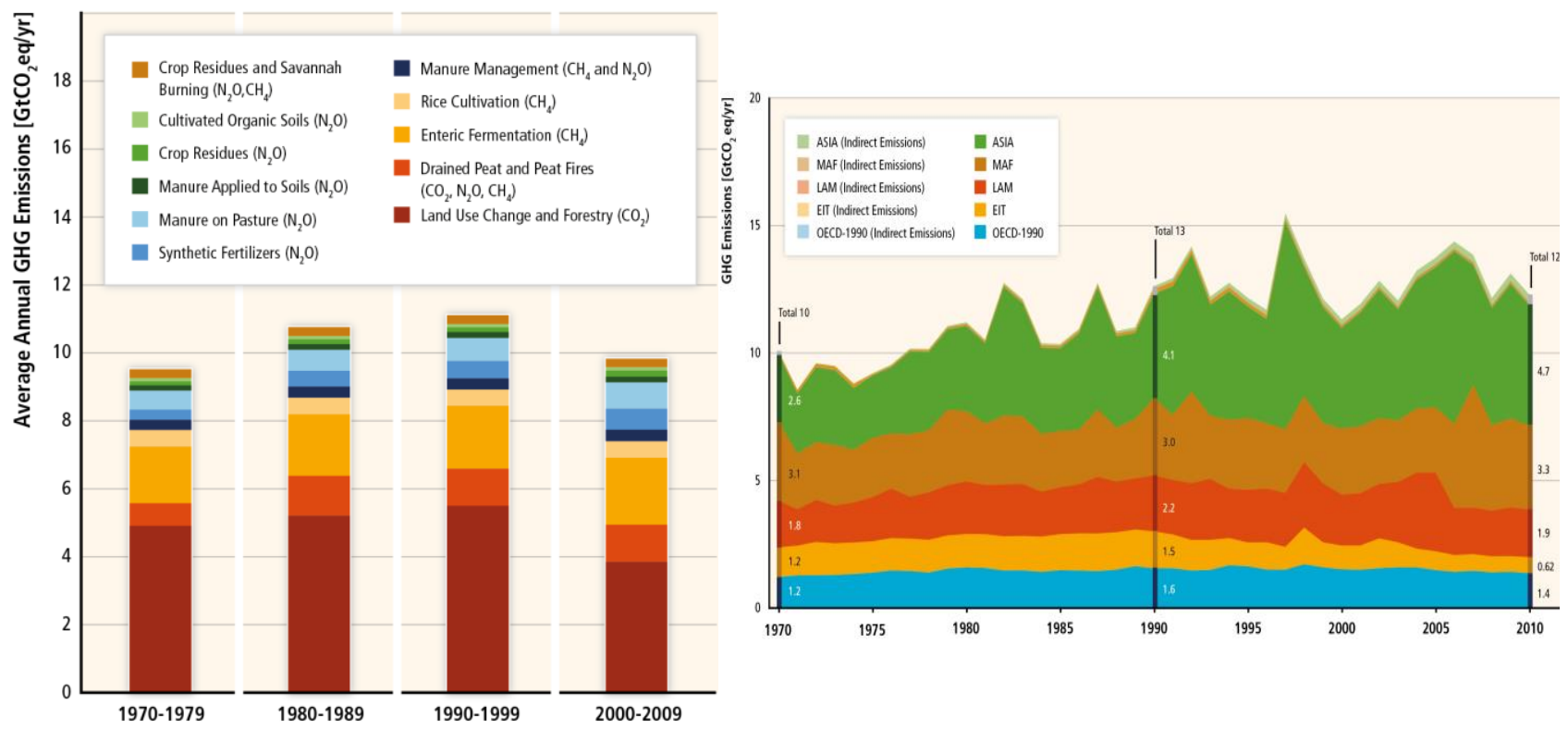

Figure 5: 1970-2010 AFOLU emissions by source (left), by region (right) Source: IPCC AR5 - WG3 "The Mitigation of Climate Change", 2014 
Indirect climate impacts are also important: these include increased competition from weeds, expansion of pathogens and insect pest ranges and seasons, and other alterations in crop agro-ecosystems. However, non-climate factors also play a key role in how agricultural systems are affected by (their vulnerability to) climate stressors; soil fertility, technology (e.g. irrigation methods, fertilizers availability), demography, and local economic and societal structures (land tenure, property rights etc. Ultimately, climate change is projected to have significant impacts on agricultural conditions, food supply, food security and development. Overall, it could result in a variety of largely adverse biophysical, ecological, economic and social impacts.

Some of these impacts have already been observed. The IPCC AR5 reports that climate trends have negatively affected wheat and maize production for many regions (medium evidence, high agreement, see Figure 6). There is also medium confidence for negative impacts on global aggregate production of wheat and maize (IPCC, 2014b). Effects on rice and soybean yields have been small in major production regions and globally. There is also high confidence that warming has benefitted crop production in some highlatitude regions, such as northeast China or the UK.
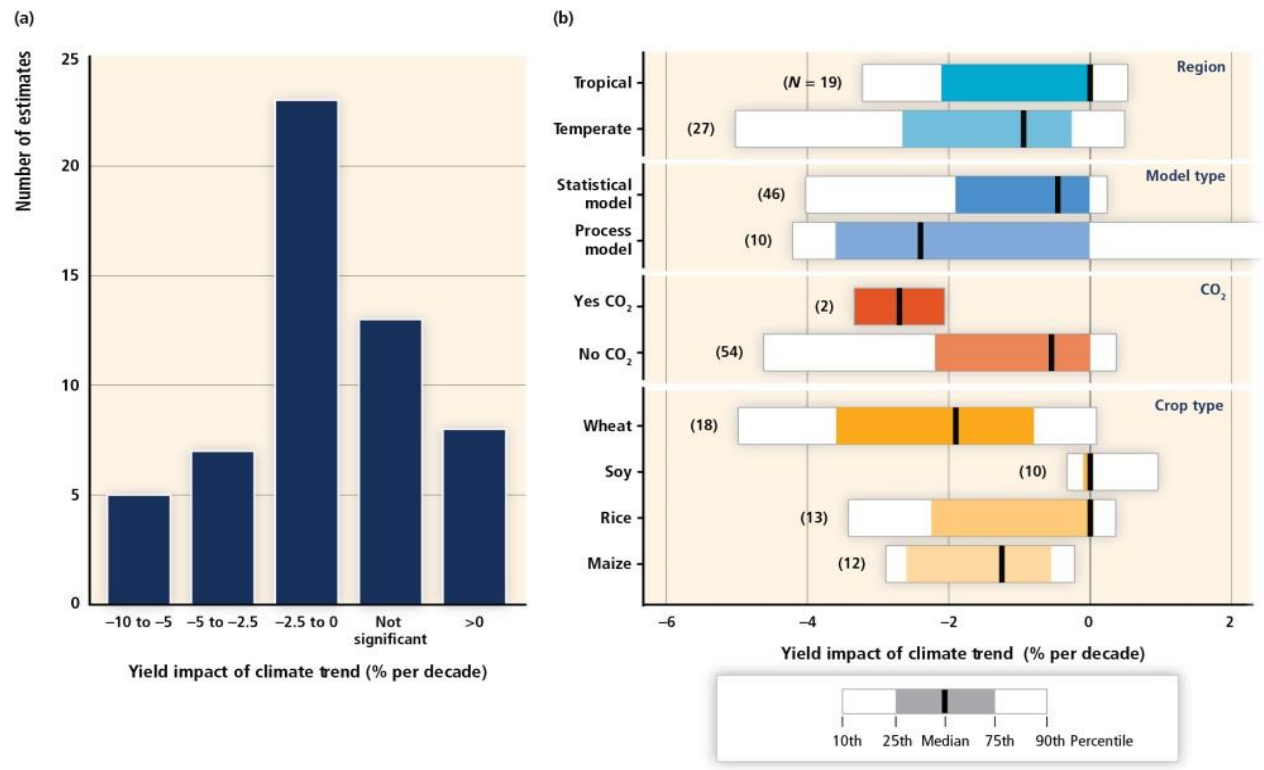

Figure 6: (a) Number of Estimates with Different Level of Impact (\% yield per decade) and (b) Boxplot of Estimates Separated by Temperate vs. Tropical Regions.

Source: IPCC AR5 - WG3 "The Mitigation of Climate Change", 2014

Based on many studies covering a wide range of regions and crops, negative impacts of climate change on crop yields have been more common than positive impacts (IPCC, 2014b). The smaller number of studies showing positive impacts relate mainly to high-latitude regions, though it is not yet clear whether the balance of impacts has been negative or positive in these regions.

Impacts form climate change are likely to become much larger in the coming decades. The net effect of future climate change on world agriculture is very likely to be negative, at least beyond a modest level of warming. Although some regions and crops will benefit, most will not. While increases in atmospheric $\mathrm{CO}_{2}$ 
are projected to stimulate growth and improve water use efficiency in some crop species, climate impacts, particularly heat waves, droughts and flooding, will likely dampen yield potential (IPCC, 2014b).

Under scenarios of high levels of warming, leading to local mean temperature increases of $3-4^{\circ} \mathrm{C}$ or higher, models based on current agricultural systems suggest large negative impacts on agricultural productivity and substantial risks to global food production and security (IPCC, 2014b). Such risks will be greatest for tropical countries, given the larger impacts in these regions, which are beyond projected adaptive capacity, and higher poverty rates compared to temperate regions.

Based on the studies cited in the IPCC AR5, it is very likely that changes in temperature and precipitation will lead to detectable increase in food prices by 2050 . Uncertainty remains high, and impacts on food prices range from $-30 \%$ to $+84 \%$ by 2050 , where negative impacts may be induced by the anyway highly uncertain fertilization effects of $\mathrm{CO}_{2}$. Climatic changes appear about as likely as not to increase prices. Clearly, uncertainty is still very large and studies reviewed by the IPCC are unable to provide a precise assessment of impacts of climate change on food prices. A better integration of agriculture and economic models is certainly need. Nevertheless, even if global yield impacts are limited, local adverse yield shocks can occur where markets are not working well to smooth or distribute the effects of the shock.

If global yields are negatively impacted by climate change and international food prices are expected to increase, also the global headcount of food-insecure people is expected to rise (IPCC, 2014b).

\section{Policy implications}

The IPCC Fifth Assessment Report delivers a very clear and simple message. To remain below $2^{\circ} \mathrm{C}$ temperature increase by the end of the century (with respect to pre-industrial levels) GHG emissions must be drastically reduced by mid-century, which implies that a large share of known fossil fuel reserves should remain underground (see Figure 7), with enormous implications for prices and asset values in the fossil fuel industry.

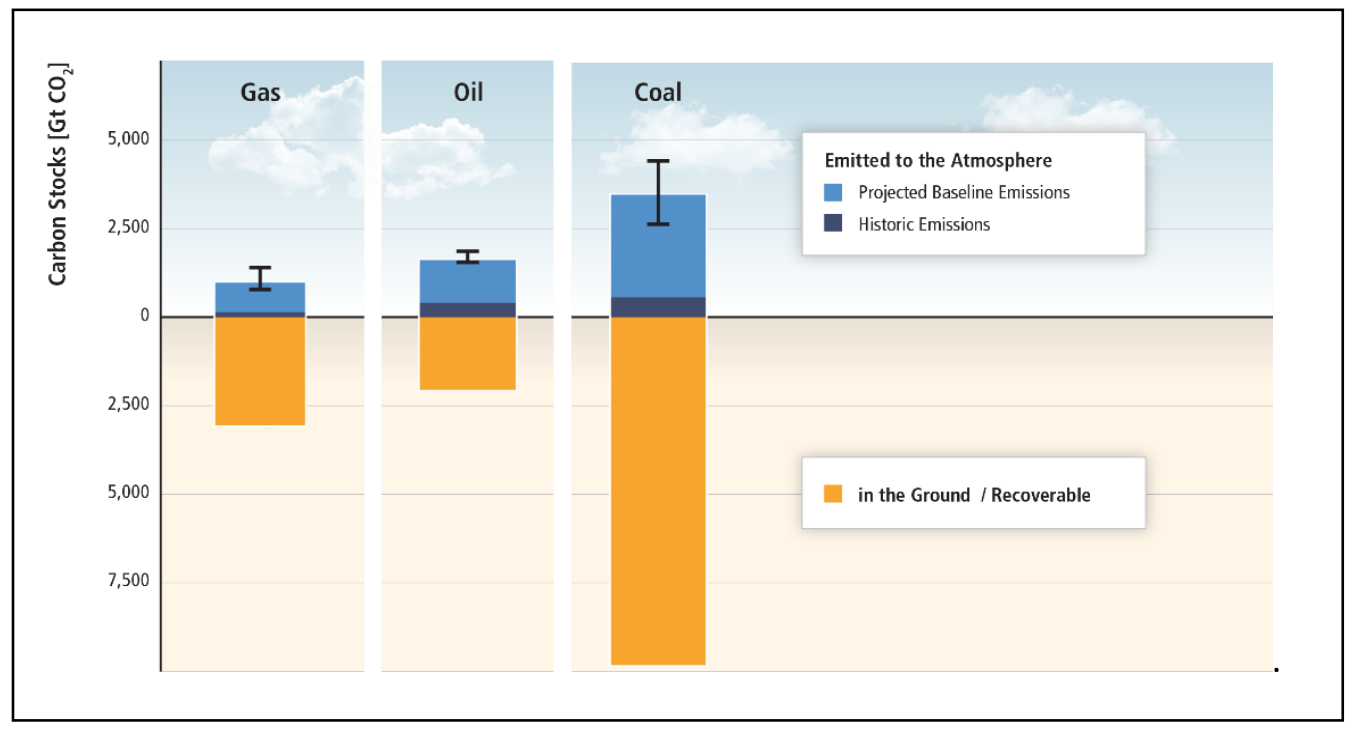

Figure 7: Stocks of carbon to be left underground.

Source: IPCC AR5 - WG3 "The Mitigation of Climate Change", 2014 
How can global GHG emissions be stabilized by 2030, following the Paris agreement, and then rapidly reduced to achieve neutrality (total emissions equal forestry and ocean absorption capacity) by 2050 ?

According to the IPCC, GHG emissions will be reduced through three main mechanisms:

(i) energy efficiency gains, favored by technological change and induced by appropriate policy measures, carbon pricing above all;

(ii) (ii) development and diffusion of renewables, mostly induced by important reductions of their costs and by improvements of their efficiency;

(iii) (iii) $\mathrm{CO} 2$ capture, storage and absorption, mostly induced by the development of new technologies that will enable our societies to remove $\mathrm{CO} 2$ from the atmosphere and to store it (or, even better, to re-use it).

These three mechanisms, and the related goals, identify three main policy measures to be adopted worldwide.

First, a price signal to be delivered to companies and investors, to drive decisions towards low carbon and energy efficiency solutions, as well as to stimulate further improvements in these solutions. This price signal can be a carbon tax, and/or an emission trading scheme, and/or the removal of subsidies to fossil fuel.

Second, carefully targeted and technology-neutral subsidies or other forms of incentives (e.g. public procurement schemes) to accelerate the deployment of renewable energy sources, thus achieving economies of scale and efficiency improvements, particularly on storage devices.

Third, the establishment of a global R\&D effort to develop technologies to address all difficulties related to the largescale deployment of renewables, to the implementation of carbon capture and sequestration plants, and to the removal of $\mathrm{CO} 2$ from the atmosphere. According to the Apollo project (Cf. King et al., 2015), this plan would require leading governments to invest a total of $\$ 15$ billion a year in research, development and demonstration of clean energy (that compares to the $\$ 100$ billion currently invested in defence R\&D globally each year). According to another study (Bosetti et al., 2011), the required investment would be $\$ 50$ billion a year, which amounts to about $0.08 \%$ of World GDP, a level that energy-related R\&D achieved in the $80 \mathrm{~s}$ (but since then declined sharply to reach about $0.02 \%$ of World GDP today). This coordinated R\&D plan can also help bring energy bills down for billions of consumers.

As of today, renewable energy gets less than $2 \%$ of publicly funded R\&D and the private sector spends relatively small sums on clean energy research and development.

Notwithstanding the aforementioned mitigation efforts, GHG emission reductions will be too slow to prevent climate change to affect heavily our socio economic systems, particularly in vulnerable regions. Hence, in addition to mitigation investments, it will become necessary to spend on climate-related damages to repair, infrastructures to re-build, and measures to protect our societies and ecosystems from the main impacts of climate change.

\section{Investments and climate finance}

Substantial reductions in GHG emissions would require large changes in investment patterns. Mitigation scenarios in which policies stabilize atmospheric concentrations (without overshoot) in the range from 430 
to $530 \mathrm{ppm}$ CO2eq by 2100 lead to substantial shifts in annual investment flows during the period 20102029 compared to baseline scenarios (see Figure 8).

Over the next two decades (2010 to 2029) annual investment in conventional fossil fuel technologies associated with the electricity supply sector would decline by about USD 30 (2-166) billion (median: -20\% compared to 2010), while annual investment in low carbon energy supply (i.e., renewables, nuclear and electricity generation with carbon capture and storage) would rise by about USD 147 (31-360) billion (median: $+100 \%$ compared to 2010 ). Annual investments should reach 400 billion USD per year between 2030 and 2050 (IPCC, 2014). Notice that 400 billions per year are equivalent to about $0.5 \%$ of gross world product (GWP) in 2013.

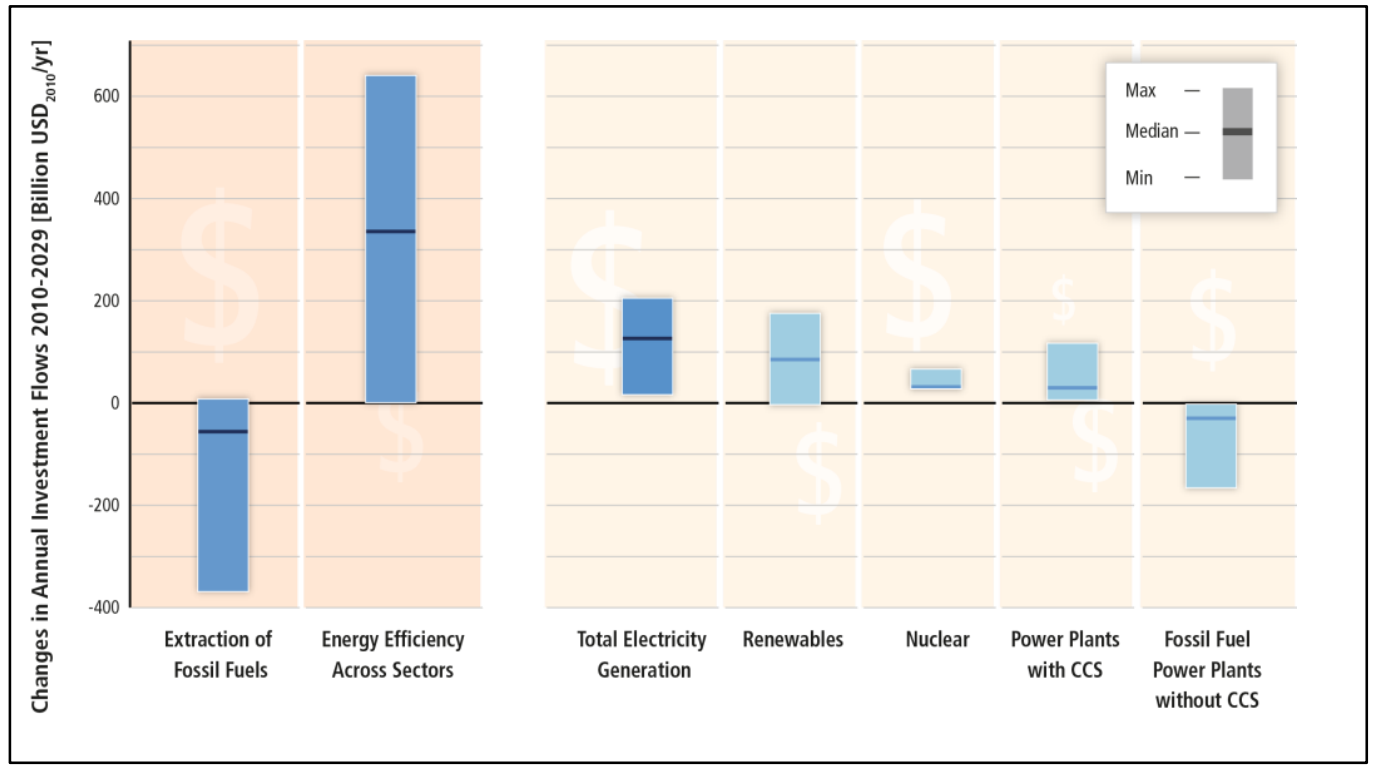

Figure 8: Change of investment patterns to achieve the $2^{\circ} \mathrm{C}$ target Source: IPCC AR5 - WG3 "The Mitigation of Climate Change", 2014

In addition, annual incremental energy efficiency investments in transport, buildings and industry would increase by about USD 336 (1-641) billion, frequently involving modernization of existing equipment. For comparison, global total annual investment in the energy system is presently about USD 1200 billion.

As previously explained, about 50 billion USD per year in 2030 (0.08\% of global GDP in 2030) should be invested in climate related Research \& Development (Cf. Bosetti et al. 2011; OECD, 2009). This is equivalent to the resources invested in energy-related Research \& Development in the '80s.

Finally, putting a price on carbon will provide markets with the policy signals needed to invest in climate solutions. At the UN Summit on climate held in New York in September 2014, seventy-three national Governments, 11 regional governments and more than 1,000 businesses and investors signaled their support for pricing carbon. Together these leaders represent 52 per cent of global GDP, 54 per cent of global greenhouse gas emissions and almost half of the world's population. Some leaders agreed to join a new Carbon Pricing Leadership Coalition to drive action aimed at strengthening carbon pricing policies and redirecting investment. More than 30 leading companies announced their alignment with the Caring for 
Climate Business Leadership Criteria on Carbon Pricing. There is therefore hope that clear price signals will induce the right flow of investments in the coming decades. But we need price signals to be implemented soon to avoid locked-in undesirable investments by the time the clear price signals are there.

Most importantly, a solid trajectory of price signals would help re-direct planned investments towards lowcarbon options. Around US\$90 trillion is likely to be invested in infrastructure in the world's urban, land use and energy systems in the next two decades. Namely, about 5-6 trillion a year. How these investments are managed will shape future patterns of growth, productivity and living standards. Hence, the real objective is to provide incentives to redirect investments designed to meet increasing demand rather than climate concerns. The development of cities in particular will be crucial. Cities generate around $80 \%$ of global economic output, and around $70 \%$ of global energy use and energy-related GHG emissions. How the world's largest and fastest-growing cities develop will be critical to the future path of the global economy and climate.

\section{Conclusions}

Governments start realizing that climate change can hinder economic development. Consequently, climate policy is no longer seen as an environmental policy, but rather as a development policy, necessary to guarantee prosperity to large fractions of world population.

Countries at all levels of income have therefore the opportunity to build long-lasting economic growth and, at the same time, to reduce the risks of climate change. This is made possible by structural and technological changes unfolding in the global economy, and opportunities for greater economic efficiency.

The potential for innovation is vast. The capital for the necessary investments is not yet available, but it is increasing. In 2014, \$384 have been invested in climate related projects, mostly for mitigation (93\%) and, more specifically, for renewable power plants. Additional resources may become available if private investors and markets are given the right price signals. What is needed is strong political leadership and credible, consistent, policies. The real issue is re-directing investments and increasing expenditures towards low carbon options. This is why long term, credible and stable policy signals are crucial. Managing a sustainable transition is the key test of "strong political leadership".

Some first steps into this direction are promising. Leaders from 19 countries and 32 partners from Government, regional organizations, development institutions and private investors committed to creating an 8,000-kilometer-Iong African Clean Energy Corridor. This will reduce both energy poverty, thus enhancing economic development, and GHG emissions in the Africa region. The Global Alliance for ClimateSmart Agriculture, comprised of 16 countries and 37 organizations, was launched to enable 500 million farmers worldwide to practice climate-smart agriculture by 2030. Leaders of the oil and gas industry, along with national Governments and civil society organizations, made an historic commitment to identify and reduce methane emissions by 2020. A second industry-led initiative was launched by leading producers of petroleum who committed to address methane as well as other key climate challenges, followed by regular reporting on ongoing efforts. A new Compact of Mayors, representing well over 2,000 cities pledged new commitments on climate action supported by new funding from public and private sources -228 cities have voluntary targets and strategies for greenhouse gas reductions, which could avoid up to 3 gigatonnes of GHG emissions per year by 2030. As for Research\&Development, the Breakthrough Energy Coalition, formed by major venture capitalists worldwide, is working to mobilize large funding commitments for basic 
and applied research, whereas Mission Innovation, announced by Bill Gates in 2015, is a global initiative to accelerate public and private clean energy innovation to address climate change, make clean energy affordable to consumers, and create green jobs and commercial opportunities. All of these initial steps are in addition to the historic pledges made at the Paris COP 21, though it remains to be seen how well the intentions are fulfilled.

There is therefore an increasing awareness that climate change policy is likely to provide multiple benefits. Good development policy needs to address inclusive growth and deep poverty eradication through a variety of channels, including increased access to energy and water, food security, improved health and education, and adequate housing. For the gains to be sustained, climate change mitigation and adaptation must inevitably be addressed. GHG emission reduction is therefore a crucial component of good development policy. Similarly, economic development is crucial for the business world, which clearly has a strong interest in contributing to control climate change, to avoid its major negative impacts on the global economy, and to profit from mitigation and adaptation related investment opportunities.

\section{References}

Bosetti, V., Carraro, C., Duval, R. and M. Tavoni (2011), "What should we expect from innovation? A modelbased assessment of the environmental and mitigation cost implications of climate-related R\&D", Energy Economics, 33 (2011) 1313-1320.

King, D., Browne, J., Layard, R., O'Donnell, G., Rees, M., Stern, N. and A. Turner (2015), A Global Apollo Programme to Combat Climate Change", Centre for Economic Performance, London School of Economics.

IPCC (2014a). Climate Change 2014: Mitigation of Climate Change. Contribution of Working Group III to the Fifth Assessment Report of the Intergovernmental Panel on Climate Change. Cambridge, United Kingdom and New York, USA: Cambridge University Press.

IPCC (2014b). Climate Change 2014: Impacts, Adaptation and Vulnerability. Contribution of Working Group II to the Fifth Assessment Report of the Intergovernmental Panel on Climate Change. Cambridge, United Kingdom and New York, USA: Cambridge University Press.

OECD (2009), "The Role of R\&D and Technology Diffusion in Climate Change Mitigation", Economics Department Working Paper No. 664, OECD, Paris.

OECD (2015), "Climate finance in 2013-14 and the USD 100 billion goal", a report by the Organisation for Economic Co-operation and Development (OECD) in collaboration with Climate Policy Initiative (CPI), OECD, Paris.

Tavoni, M. and R. Socolow (2013), "Modeling meets science and technology: an introduction to a special issue on negative emission", Climatic Change, Special Issue on Science and Policy of Negative Emission Technologies (Volume 118, Issue 1, May 2013)

UNFCCC (2015a). Synthesis report on the aggregate effect of the intended nationally determined contributions. http://unfccc.int/resource/docs/2015/cop21/eng/07.pdf.

UNFCCC (2015b), "Adoption of the Paris Agreement", Paris, France. 